\title{
Cavitation Damage Behavior in Seawater for Al-Mg Alloy Arc Thermal Spray Coating with Mg Content
}

\author{
I.C. PARK, S.J. KIM* \\ Division of Marine Engineering, Mokpo National Maritime University, \\ 91, Haeyangdaehak-Ro Mokpo-si, Jeollanam-do, 530-729, Korea
}

\begin{abstract}
$\mathrm{Al}$ arc thermal spray coating materials are widely used to prevent the corrosion of steel structure materials in marine environment. To improve the durability of the $\mathrm{Al}$ alloy thermal spray coating layer, $\mathrm{Al}-\mathrm{Mg}$ alloy arc thermal spray coating was performed with different $\mathrm{Mg}$ contents. Furthermore, the cavitation experiment was performed in natural seawater to evaluate the durability of the thermal spray coating layer, and the damaged surface was analyzed with a scanning electron microscope and a 3D microscope. As a result, the durability of the $\mathrm{Al}-\mathrm{Mg}$ alloy thermal spray coating layer improved by the addition of $\mathrm{Mg}$, and the $\mathrm{Al}-3 \% \mathrm{Mg}$ thermal spray coating layer presented the best characteristics.
\end{abstract}

DOI: 10.12693/APhysPolA.129.572

PACS/topics: 52.77.Fv, 81.15.Rs

\section{Introduction}

Steels which are the materials for ships and marine structures are vulnerable to corrosion when exposed to the severe marine environment. The corrosion of carbon steel is largely affected by fluid velocity and vortex. A faster fluid velocity leads to faster corrosion, and if it is accompanied by physical erosion, the damage speed increases significantly $[1,2]$. The metal thermal spray coating technique has been widely used for corrosion protection of steel. They are particularly useful for large steel structures such as steel bridges and marine structures that require long life. In most cases, arc thermal spray coating with $\mathrm{Al}, \mathrm{Zn}$, and $\mathrm{Al}-\mathrm{Zn}$ alloys is used. Therefore, to achieve the long life of ships and marine structures through thermal spray coating techniques, thermal spray coating wires with better durability than existing thermal spray coating materials for corrosion protection need to be developed. Han et al. [3] applied the F-Si sealant after $\mathrm{Al}$ thermal spray coating to reduce the damages of rudder, thereby improving corrosion resistance and durability. Furthermore, Kim et al. [4] applied various sealants after performing $\mathrm{Al}-\mathrm{Zn}-\mathrm{Zr}$ alloy thermal spray coating for ship materials. As a result, the excellent corrosion resistance of hybrid ceramic and fluoro-silicon sealants was verified, and fluoro-silicon was found to be a sealant with the best durability. The general practice has been to improve corrosion resistance and durability simultaneously by blocking open pores in the thermal spray coating layers through post-processing after the thermal spray coating. However, as an additional work process after thermal spray coating, post-processing has the disadvantage of increasing work time and cost. Therefore, this study was conducted to improve the durability of the conventional

*corresponding author; e-mail: ksj@mmu.ac.kr
$\mathrm{Al}$ thermal spray coating against the cavitation experiment after the $\mathrm{Al}-\mathrm{Mg}$ alloy thermal spray coating with different $\mathrm{Mg}$ contents.

\section{Materials and experimental method}

The mild steel(Fe-0.16 wt\% C-0.19 wt\% Si-0.36 wt\% $\mathrm{Mn}-0.013 \mathrm{wt} \% \mathrm{P}-0.011 \mathrm{wt} \% \mathrm{~S}$ ) which is widely used for general structures was used as the substrate, and for the surface treatment before the thermal spray coating, a rough surface was formed by performing grit blasting. In this study, arc thermal spray method was used with $\mathrm{Al}, \mathrm{Al}-3 \% \mathrm{Mg}$, and $\mathrm{Al}-5 \% \mathrm{Mg}$ wires, using a robot control system to maintain constant spray conditions of the spray gun. For the thermal spray work, an air pressure of $6.5-7 \mathrm{~kg} / \mathrm{cm}^{2}$, an output voltage of about $30 \mathrm{~V}$, an output current of about $150 \mathrm{~A}$, and a spray distance of about $200 \mathrm{~mm}$ were maintained and thickness of thermal spray coating layer was $200-250 \mu \mathrm{m}$. For this thermal spray coated specimen, the cavitation erosion tester with piezoelectric effect was used under natural seawater environment, and the experiment was conducted by opposite vibration in accordance with the modified ASTM G32 regulations. A $20 \mathrm{kHz}$ rated vibration output was generated through the electronic circuit with $60 \mathrm{~Hz}, 220 \mathrm{~V}$ power, which was supplied to the vibrator. The amplitude was maintained constant at $5 \mu \mathrm{m}$ by constant amplitude automatic control. The specimen was fixed in a holder in opposition to the horn of vibrator and a distance of $1 \mathrm{~mm}$ was maintained. To minimize the corrosion damage effect of temperature, the seawater temperature was maintained constant at $25^{\circ} \mathrm{C}$ during the cavitation experiment. Furthermore, for the weight loss analysis, the specimens were cleaned with an ultrasonic washer before and after the experiment and dried in a dryer for $24 \mathrm{~h}$. Then their weights were measured and compared. After the cavitation experiment, the surface damages of the specimens were observed with a scanning electron microscope (SEM) and a 3D microscope. For hardness 
measurement, the micro Vickers-hardness tester was used to measure the surface of the thermal spray coating more than 10 times and their average was determined.

\section{Results and discussion}

Figure 1 presents the porosity analysis and surface hardness determined through an observation of crosssections on the $\mathrm{Al}$ and $\mathrm{Al}-\mathrm{Mg}$ alloy thermal spray coating layers. Many pores were observed in every thermal spray

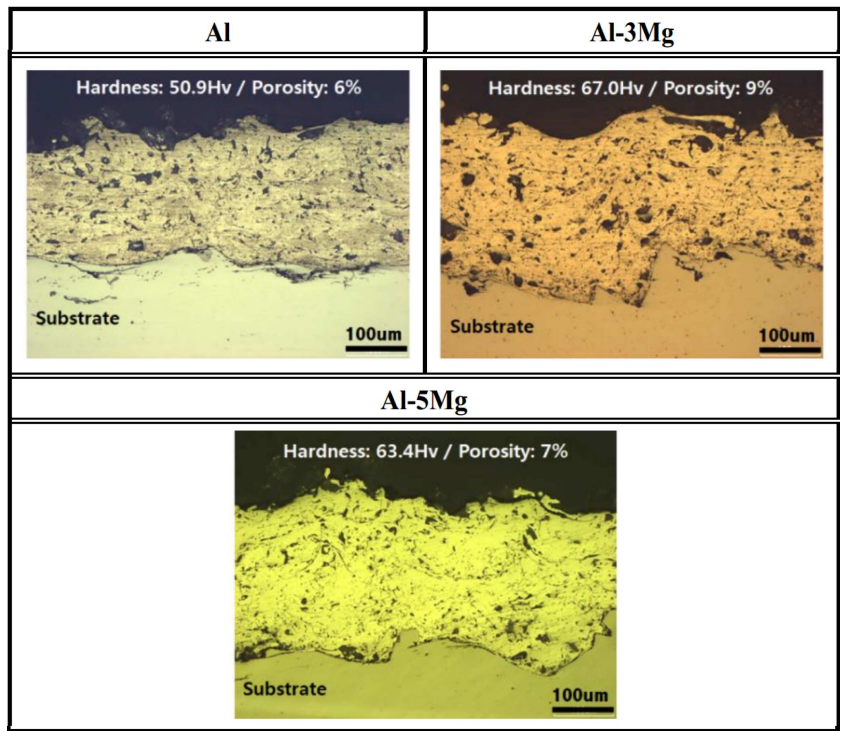

Fig. 1. Cross-section morphologies of thermal spray coating layers on the steel.

coating layer, and the porosities of all the thermal spray coating layers ranged from 6 to $9 \%$, indicating very small differences. As the general porosity of $\mathrm{Al}$ and $\mathrm{Zn}$ thermal spray coating layers is about $5-10 \%$, the thermal spray coating layers used in this study would have the characteristics of general spray coating layer [5]. The pore size and distribution of the thermal spray coating layer for the cross-section are major factors that affect the characteristics of the thermal spray coating layer. The cause of such pores in the thermal spray coating layer is the peculiarity of the splat lamination, which generates coarse pores between imperfect splats. Medium-sized pores are generated when the molten droplets collide with the substrate and are spread, the follow-up droplets above the bouncing droplets from the corners of splats collide with the coagulated particles and form splats. Furthermore, the gas captured in the molten droplets collides with the substrate and forms splats and is discharged. As a result, microsized pores in the splats are isolated [6]. Therefore, thermal spray coating inevitably includes pore defects due to the nature of the process. This not only decreases the bonding strength between particles, the adhesion strength with substrate, and corrosion resistance, but also separates the coating layer by providing a path for the seawater to penetrate into the substrate or by corrosive damages inside the coating layer. As a result, the pores in the spray coating layer will lower the cavitation resistance in seawater solution. Next, to compare the surface hardness values of each spray coating layer, $\mathrm{Al}$, $\mathrm{Al}-3 \% \mathrm{Mg}$, and $\mathrm{Al}-5 \% \mathrm{Mg}$ spray coatings were measured at $50.9 \mathrm{Hv}, 67.0 \mathrm{Hv}$, and $63.4 \mathrm{Hv}$, respectively. The hardness value of the $\mathrm{Al}-\mathrm{Mg}$ alloy spray coating was higher than that of the Al spray coating layer, which seems to be due to the alloy element $\mathrm{Mg}$. Through these hardness measurements, the resistance of materials against physical external forces can be inferred, and hardness, corrosion resistance, and cavitation resistance are known to have a certain degree of correlation [7]. Therefore, it is expected that the $\mathrm{Al}-3 \% \mathrm{Mg}$ spray coating which had the greatest hardness value will show the best cavitation resistance.

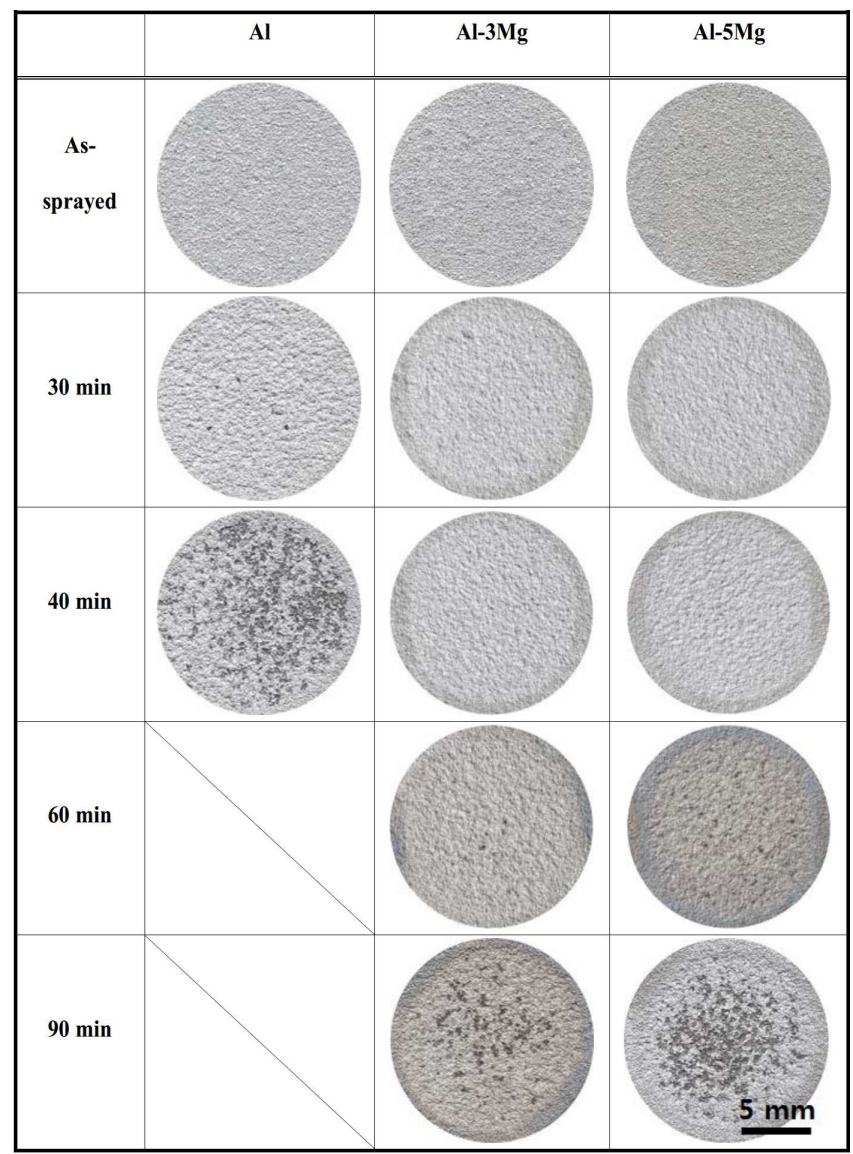

Fig. 2. Surface morphologies after cavitation experiment of thermal spray coatings in sea water.

Figure 2 shows the surface shapes of the $\mathrm{Al}$ and $\mathrm{Al}-$ $\mathrm{Mg}$ alloy spray coating layers according to the cavitation experiment time in seawater solution. The cavitation damage occurred in a horn shape. The surface damage amount generally increased due to the accumulation of the impact energy that occurs when the bubbles break according to the progress of the experiment time. When the experiment times of the $\mathrm{Al}$ and $\mathrm{Al}-\mathrm{Mg}$ thermal spray coating layers elapsed $30 \mathrm{~min}$ and $60 \mathrm{~min}$, respectively, local erosion damages were observed which looked like black dots on some parts due to the impact pressure 
of the bubble breakdown. This indicates that due to the continued progress of surface damages, the thermal spray coating layer thickness gradually became thinner, approaching close to the substrate. Because of this, when the experiment times elapsed $40 \mathrm{~min}$ and $90 \mathrm{~min}$, respectively, the impact pressure of bubble breakdown affected the interface between the coating layer and the substrate, which weakened the cohesive strength of the interface and resulted in the rapid delamination damage of the thermal spray coating layer. As a result, a large surface damage of the substrate was observed even by naked eye. Furthermore, when the surface damage trend after $30 \mathrm{~min}$ of experiment time was examined, the damage started and progressed from the center of the specimen. In the study of Won et al. [8], the cavity cluster had a spray shape of a trumpet-shaped pillar from the horn surface. Almost no fluid flow was detected at the edge of the horn, and the closer to the center of the horn, the higher the fluid velocity tended to become. This agreed with the findings of the study by Hansson and Morch [9] which described that the surface damage progressed as the hemispherical cluster on the horn surface was destroyed. As a result delamination of the thermal spray coating layer occurred at the center of the specimen intensively and the steel was exposed.

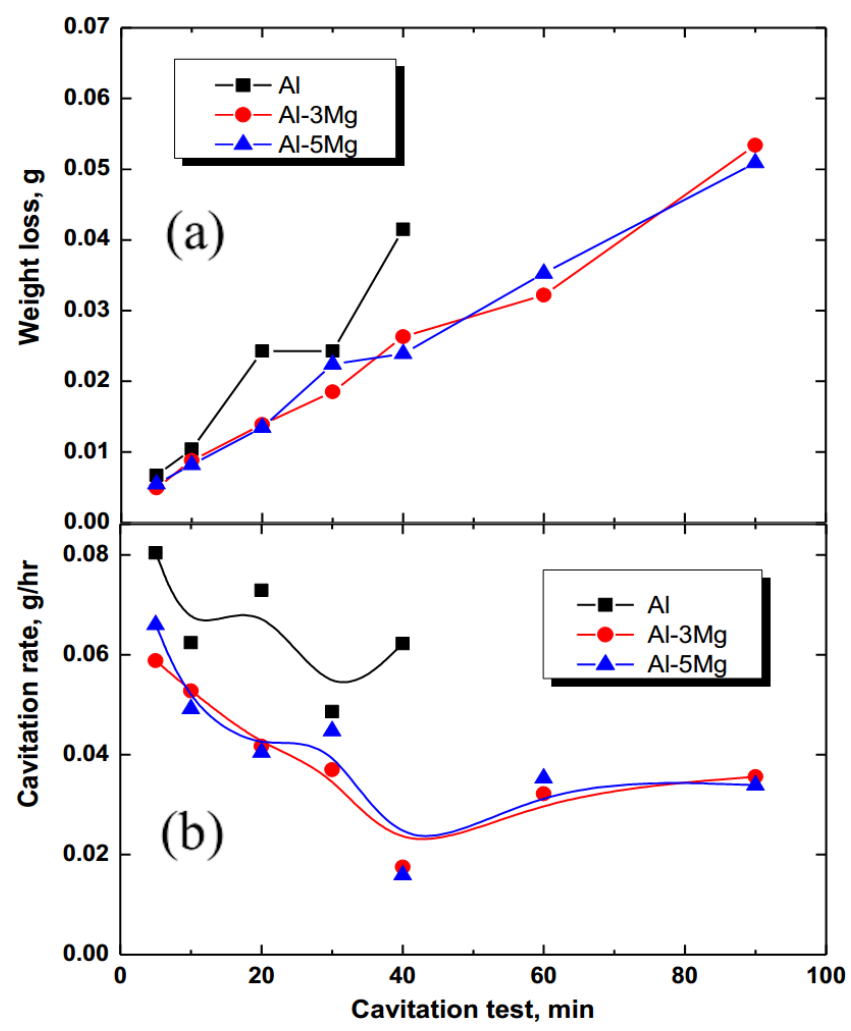

Fig. 3. Weight loss (a) and cavitation rate (b) after cavitation experiment of thermal spray coatings in sea water.

Figure 3 depicts the weight loss and cavitation rate of the $\mathrm{Al}$ and $\mathrm{Al}-\mathrm{Mg}$ alloy thermal spray coating layers with the cavitation experiment time in seawater solution. As shown in Fig. 3a, the weight loss increased almost proportionally with the progress of the experiment time. Therefore, the surface damage in the thermal spray coating layer was continuously caused by the bubble breakdown impact pressure and the micro-jet during the experiment time. The Al thermal spray coating layer presented poor durability, with larger weight loss compared to the $\mathrm{Al}-\mathrm{Mg}$ alloy thermal spray coating when the same experiment time was applied. As shown in Fig. 3b, the cavitation rates of $\mathrm{Al}$ and $\mathrm{Al}-\mathrm{Mg}$ thermal spray coating layers decreased from the beginning of experiment until $30 \mathrm{~min}$ and $40 \mathrm{~min}$, respectively. After this, the cavitation rates increased a little. The reason that the cavitation rate decreased for a certain experiment time is that as the experiment progressed, pit damages on the surface increased to which bubbles were adsorbed and collided with bubbles that occurred later and extinguished, and this generated a cushion effect. Furthermore, the cavitation rate increased after some time, because as the surface delamination of the thermal spray coating layer continued, the thickness of the residual thermal spray coating layer became reaching the interface between the substrate and the thermal spray coating layer, which weakened the thinner and closer to the substrate. As a result, the bubble breakdown impact pressure and micro-jet effects reached the interface between the substrate and the thermal spray coating layer, which weakened the cohesive strength of the interface. Thus, surface damage was accelerated by cavitation experiment and the cavitation rate increased. Consequently, the Al thermal spray coating layer showed the largest slope in the weight loss and the largest cavitation rate during the experiment time, indicating significantly poorer cavitation resistance compared to the $\mathrm{Al}-\mathrm{Mg}$ alloy thermal spray coating layer. Metal materials generally undergo plastic deformation and work hardening during the early stage. Thus, they have a incubation period when erosion is stagnant, an acceleration period when the cavitation rate gradually increases, a deceleration period when the cavitation rate decreases due to the buffer effect of the bubbles after the maximum part with the largest erosion of the material, and a steady period when the erosions spread to the entire surface of the material and the cavitation rate becomes almost constant [10]. The incubation period in this study was within $5 \mathrm{~min}$, but the accurate time could not be confirmed. However, Kim et al. [11] conducted a cavitation experiment using 5000 series $\mathrm{Al}-\mathrm{Mg}$ alloy and 6000 series $\mathrm{Al}-\mathrm{Mg}-\mathrm{Si}$ alloy and revealed that the incubation period was less than 30 min. The incubation period of the thermal spray coating layer is shorter because the micropores that inevitably exist in the thermal spray coating layer easily grow into pit damages. Furthermore, the thermal spray coating layer is formed in a lamella structure and the cohesive strength between splats is weaker than single body materials, generating splat delamination [12]. Therefore, the cavitation resistance of the thermal spray coating layer is expected to 
decrease due to the difference of structural characteristics compared to the same single-body material.

Figure 4 exhibits the surface damages of the $\mathrm{Al}$ and $\mathrm{Al}-\mathrm{Mg}$ alloy thermal spray coating layers with the cavitation experiment time in seawater solution, which were observed with a SEM. It has been known that the cause of cavitation damages is the simultaneous action of shock waves and the micro-jet from the bubble breakdown [13]. This is because the micro-jet and shock waves move at high speeds of $500-600 \mathrm{~m} / \mathrm{s}$ and when bubbles break up on the sold surface, it generates a large impact pressure of several GPa, causing fatigue, breakdown, and loss of materials $[14,15]$. Thus, when the impact energy generated by the bubble breakdown is delivered to the material surface, it generates an internal stress and when this stress exceeds the limit, damages are generated. When the surface is observed before experiment, microstructural defects were observed as black spots, which were formed during the thermal spray coating process. The microstructural defects on the surface of the thermal spray coating layer act as the nucleus of bubble generation during the early stage of experiment, which develop into small erosive pits.p

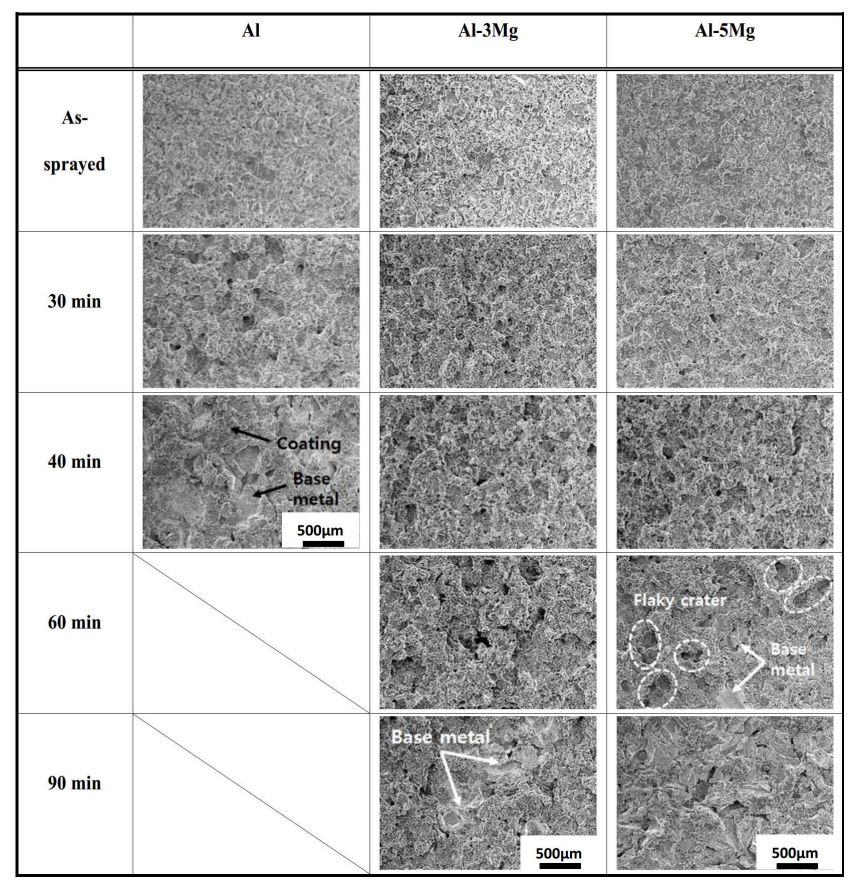

Fig. 4. Surface morphologies after cavitation experiment of thermal spray coatings in sea water.

Furthermore, as the experiment time elapsed, the numbers and sizes of pits and craters on the surface of the thermal spray coating layer increased, which leads to the generation and breakdown of more bubbles inside or surrounding them, which further worsened the surface damages. After that, in the case of the Al thermal spray coating layer, the surface damages progressed rapidly at $40 \mathrm{~min}$ of experiment time and the substrate was exposed on the surface. In the case of the $\mathrm{Al}-3 \% \mathrm{Mg}$ thermal spray coating layer, many craters of damages along the depth were observed at $60 \mathrm{~min}$ of experiment time. The reason for this seems to be that the damage of the pure thermal spray coating layer was combined with the substrate damage by grit blasting before the thermal spray coating was exposed as the thermal spray coating layer was removed, thus revealing a large surface damage. After that, at the experiment time of $90 \mathrm{~min}$, the delamination damage of the thermal spray coating layer progressed further and the substrate was exposed, while the remaining thickness of the thermal spray coating layer was relatively thin. Next, in the case of the $\mathrm{Al}-5 \% \mathrm{Mg}$ thermal spray coating, the pits that occurred in the early stage generally grew along the depth until $40 \mathrm{~min}$ of experiment time. After that, however, at $60 \mathrm{~min}$ of experiment time, the entire surface of the thermal spray coating layer quickly underwent delamination damages, exposing part of the substrate. This appears to be a flaky crater that was formed as the thermal spray coating layer was delaminated in a bulk shape rather than a crater that was generated by steadily growing pits [13]. At $90 \mathrm{~min}$ of experiment time, the surface damages progressed further and there was almost no thermal spray coating layer on the surface and the substrate was exposed on the entire surface. Thus, the substrate formed by grit blasting accounted for most of the surface shape rather than the thermal spray coating layer. Thus, the $\mathrm{Al}-5 \% \mathrm{Mg}$ thermal spray coating layer exhibited a different damage mechanism in comparison with the $\mathrm{Al}$ and $\mathrm{Al}-3 \% \mathrm{Mg}$ thermal spray coating layers described above.

The reason for this seems to be that the pits that developed locally in the early stage of the cavitation experiment steadily grew along the depth with the elapsed experiment time and reached the substrate. Therefore, as the interface between the substrate and the thermal spray coating layer was exposed to the impact pressure of bubble breakdown, it led to the rapid delamination of the thermal spray coating layer at $60 \mathrm{~min}$ of experiment time and formed flaky craters. This damage trend occurred only in the $\mathrm{Al}-5 \% \mathrm{Mg}$ thermal spray coating layer which seems to be due to the difference in the $\mathrm{Mg}$ content rather than pores. In marine environment, the 5000 series $\mathrm{Al}-\mathrm{Mg}$ alloy is most widely used in ships and marine structures among the $\mathrm{Al}$ alloy materials due to excellent strength and corrosion resistance. In this study, the $\mathrm{Al}-$ $5 \% \mathrm{Mg}$ thermal spray coating layer is easily penetrated by highly corrosive seawater not only due to the nature of the coating layer, but also due to the repeated impact pressure of bubble breakdown on local sites, making the material more sensitive to stress corrosion cracking.

Figures 5 and 6 present the surface damages of the $\mathrm{Al}$ and $\mathrm{Al}-\mathrm{Mg}$ alloy thermal spray coating layers with the cavitation experiment time in seawater solution, which were observed with a 3D microscope.

Figure 5 shows a general trend of increasing surface damage depth with the elapsed experiment time. This agrees with the surface damage trend revealed by the 


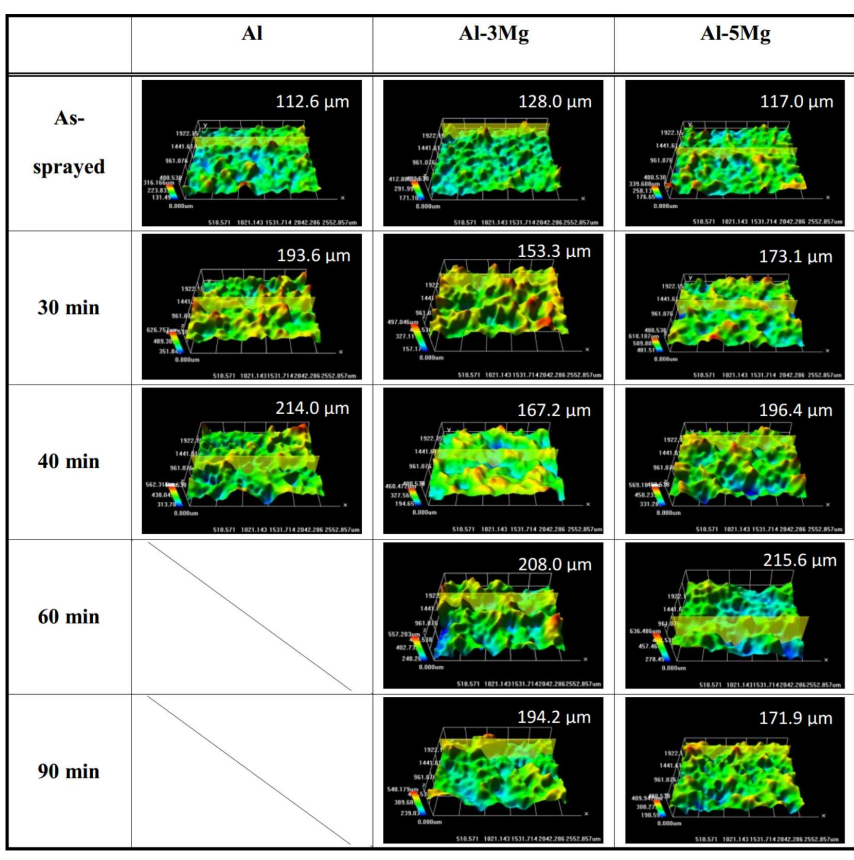

Fig. 5. 3D analysis after cavitation experiment of thermal spray coatings in sea water.

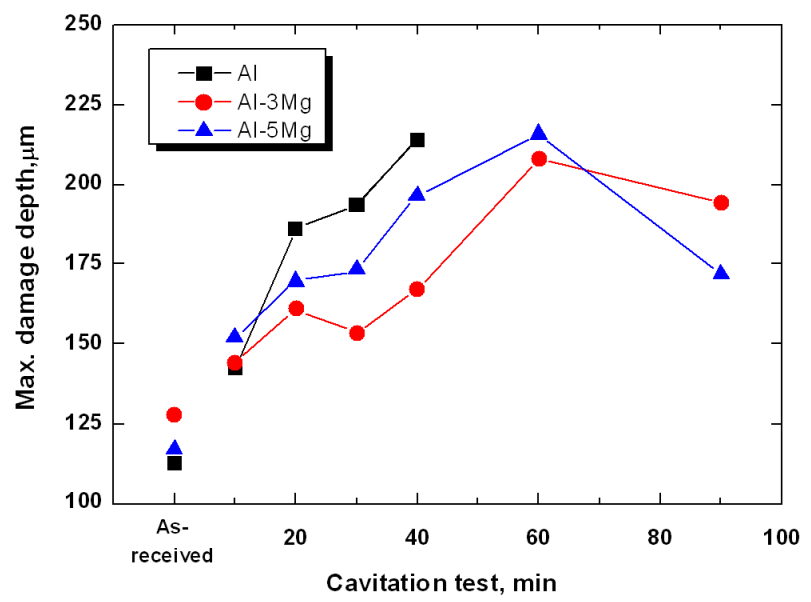

Fig. 6. Maximal damage depth after cavitation experiment of thermal spray coatings in sea water.

SEM. The damage depth increased due to the growth of micropits during the early stage of experiment. After that, the pits grew to craters and the surface damage depth increased further.

As shown in Fig. 6, the $\mathrm{Al}$ thermal spray coating layer exhibited the largest surface damage depth because of the surface roughness due to grit blasting before the thermal spray work even though most of the thermal spray coating was delaminated and the substrate was exposed at $40 \mathrm{~min}$ of experiment time. For the $\mathrm{Al}-3 \% \mathrm{Mg}$ thermal spray coating layer, damage trend in the width direction was dominant rather than the depth direction after the crater generation compared to the $\mathrm{Al}$ and $\mathrm{Al}-5 \% \mathrm{Mg}$ thermal spray coating layers. As a result, at $30 \mathrm{~min}$ of experiment time, the surface damage depth decreased despite continuous surface delamination. Furthermore, at $60 \mathrm{~min}$ of experiment time, the substrate damaged by grit blasting was exposed, which rapidly increased the surface damage depth as the substrate was exposed. Then at 90 min of the experiment time, the delamination damage of the thermal spray coating layer continued over the experiment end, leading to a thinner coating layer, showing a decreasing trend of the surface damage depth.

On the other hand, the $\mathrm{Al}-5 \% \mathrm{Mg}$ thermal spray coating layer exhibited a tendency similar to the $\mathrm{Al}-3 \% \mathrm{Mg}$ thermal spray coating layer. In the case of the $\mathrm{Al}$ and $\mathrm{Al}-3 \% \mathrm{Mg}$ thermal spray coatings, after the pits grew to craters, damages along the depth and width directions were repeated and even the substrate was damaged. However, in the case of the $\mathrm{Al}-5 \% \mathrm{Mg}$ thermal spray coating layer, the surface damage depth continuously increased until $40 \mathrm{~min}$ of the experiment time as local pits that were generated in the early stage of experiment progressed along the depth direction rather than along the width direction. After that, at the experiment time of $60 \mathrm{~min}$, the surface damage depth still showed a continuous increasing trend. The surface of the thermal spray coating layer became very rough due to the delamination of the thermal spray coating layer of the sharp flaky crater shape rather than the effect of the pit damage along the depth, but grit blasting of the exposed metal was also added and the greatest surface damage depth was measured. Then at the experiment time of $90 \mathrm{~min}$, the surface damage depth tended to decrease because there was only a small remaining thermal spray coating layer due to the continuous delamination phenomenon of the thermal spray coating layer. However, as the exposed area of the substrate increased, the surface damage depth was relatively large due to the effects of the grit blasting damages which appeared sharp and deep. Consequently, the Al thermal spray coating layer presented the poorest durability as it showed the largest slope within the shortest time. Furthermore, for the first 60 min of experiment time when the effect of the exposed substrate was relatively small, the $\mathrm{Al}-3 \% \mathrm{Mg}$ thermal spray coating layer exhibited the smallest slope, indicating the smallest surface damage by cavitation.

\section{Conclusion}

1. The surface hardness of the $\mathrm{Al}-\mathrm{Mg}$ alloy thermal spray coating layers were greater than that of the $\mathrm{Al}$ thermal spray coating layer due to the alloy element $\mathrm{Mg}$.

2. The Al thermal spray coating layer exhibited the largest change in weight loss and surface damages that exposed the substrate within a short time, indicating a poorer cavitation resistance compared to the $\mathrm{Al}-\mathrm{Mg}$ alloy thermal spray coating.

3. In the case of the $\mathrm{Al}$ and $\mathrm{Al}-3 \% \mathrm{Mg}$ thermal spray coatings, the pits grew and developed into craters, 
thereby damaging even the substrate. On the other hand, for the $\mathrm{Al}-5 \% \mathrm{Mg}$ thermal spray coating layer, the delamination damage of the thermal spray coating layer of the flaky crater shape was delaminated after local pits progressed along the depth.

4. The $\mathrm{Al}-\mathrm{Mg}$ alloy thermal spray coating layer at the surface damage depth analysis showed a smaller surface damage depth compared to the Al thermal spray coating layer. In particular, the $\mathrm{Al}-3 \% \mathrm{Mg}$ thermal spray coating layer exhibited a smaller surface damage depth.

\section{References}

[1] Z. Sun, X.Q. Kang, X.H. Wang, Mater. Des. 26, 59 (2005).

[2] E. Heitz, Corrosion 47, 135 (1991).

[3] M.S. Han, S.J. Lee, S.K. Jang, S.J. Kim, Corros. Sci. Technol. 9, 317 (2010).

[4] S.J. Kim, S.J. Lee, I.J. Kim, S.K. Kim, M.S. Han, S.K. Jang, Trans. Nonferrous Met. Soc. China 23, $1002(2013)$
[5] S.J. Kim, S.J. Lee, Trans. Nonferrous Met. Soc. China 21, 2798 (2011).

[6] Y.Q. Zhang, Z.X. Ding, Y. Fan, China Surf. Eng. 6 , 25 (2005).

[7] C.T. Kwok, F.T. Cheng, H.C. Man, Mater. Sci. Eng. A 290, 74 (2000).

[8] D.S. Won, K.S. Jeon, Y.T. Hho, J.H. Lee, Corros. Sci. Technol. 23, 215 (1994).

[9] I. Hansson, K.A. Morch, J. Appl. Phys. 51, 4651 (1980).

[10] A. Thiruvengadam, H.S. Preiser, J. Ship Res. 8, 39 (1964).

[11] S.J. Kim, K.H. Kim, S.J. Lee, Corros. Sci. Technol. 10, 136 (2011)

[12] L. Hauschmann, J. Siegi, J. Karlik, I. Kunes, P. Chraska, in: Proc. Int. Thermal Spray Conf and Exposition, Ed. C.C. Berndt, ASM International, Orlando 1992, p. 723

[13] G. Hou, X. Zhao, H. Zhou, J. Lu, Y. An, J. Chen, J. Yang, Wear 311, 81 (2014).

[14] M.C. Park, K.N. Kim, G.S. Shin, S.J. Kim, Wear 274, 28 (2012).

[15] A.K. Krella, Prog. Org. Coat. 70, 318 (2011). 